\title{
Redefinição de Espaços e Papéis na Gestão de Serviços Públicos. Fronteiras e Funções da Regulação Social
}

\author{
Élvia M. Cavalcanti Fadul
}

\begin{abstract}
RESUMO
Ao assistirmos às transformações nos mercados de serviços urbanos, com fenômenos como privatização, liberalização e globalização que questionam os serviços públicos e as próprias funções do Estado, uma questão nos parece fundamental: como assegurar direitos dos cidadãos e eficiência produtiva da iniciativa privada, garantindo a eqüidade territorial? $\mathrm{O}$ Estado precisa de políticas capazes de manter os princípios de continuidade, regularidade, igualdade de acesso, não discriminação, não exclusão e interesse coletivo dos serviços públicos, e desenvolver mecanismos que lhe permita privatizar sem perder o domínio sobre o espaço público e o controle do papel social dos serviços. Nesse sentido, o papel da regulação social na manutenção do equilíbrio entre atores que têm objetivos diferenciados e estratégias específicas é fundamental. Busca-se, neste artigo, renovar a reflexão acerca dos rumos que pode tomar esta fase atual de revisão por que passam os serviços públicos e de suas consequiências possíveis, procurando, também, abrir perspectivas para a compreensão das novas configurações dos modelos de gestão dos serviços públicos que se delineiam.
\end{abstract}

Palavras-chaves: gestão pública, serviços públicos, regulação social, privatização, eqüidade territorial.

\section{ABSTRACT}

The market of urban services is been transformed by process like privatization, deregulation and globalization. This changes bring about a crucial question: how to guarantee citizens' rights and efficiency within the private sector together with spatial equity? The state needs to build up polices able to maintain principles like continuity, regularity, equality of access, non-discrimination, non-exclusion and collective interest of the public services, together with the control of social role of the public services. The role of social regulation in the maintenance of the balance between actors with controversial objectives and strategies is crucial. This article deals with the current development of the public services. Furthermore, it evaluates the likely results of the public services shaped according to this new format. It searches also to open some perspectives for the understanding of the new management features of the public services.

Key words: public management, public services, social regulation, privatization, spatial equity. 


\section{INTRODUÇÃO}

A inserção do setor privado na produção de serviços públicos, sob formas jurídicas variadas, não é mais novidade. Venda dos ativos públicos a empresas privadas, transformação de administrações públicas em sociedades de economia mista, delegação através de contratos de prestação de serviços, concessão, permissão, terceirização ou parceria são expressões amplamente utilizadas, com bastante familiaridade, pelos administradores públicos de qualquer esfera de governo, e temas exaustivamente discutidos nos meios profissionais, políticos e acadêmicos.

Em função da crise, das reestruturações econômicas e sociais, das mudanças nos modos de vida e nos padrões de consumo, inúmeros países estão sendo confrontados por questões similares. De um lado, o dever de atender, com recursos orçamentários limitados, às demandas que se ampliam; do outro, a evolução de múltiplos fatores (internacionalização, comunicações ultra-rápidas, desenvolvimento da mídia, exigências crescentes das populações, e outros) que reduzem, cada vez mais, a capacidade de governar. Quase todos os países ocidentais buscam maior eficiência e produtividade dos serviços públicos e melhor atendimento aos cidadãos.

Nesse contexto de aparente transição, o que surge, como dado relativamente pouco explorado, são os termos em que esta questão se coloca atualmente, nos grandes centros urbanos. Torna-se difícil antever os desdobramentos dessa onda de fenômenos como a privatização, a liberalização e a globalização de mercados, que provocam transformações substanciais tanto na redefinição de políticas econômicas e sociais quanto nas formas de provisão, de organização, de gestão, de produção, de consumo e de regulação desses serviços.

É difícil dizer se o que está ocorrendo nesse momento é necessidade real de renovação do serviço público ou desejo de mudar apenas as estruturas envelhecidas e inadaptadas das administrações públicas. Até que ponto os países, estimulados por esses fenômenos, ou por pressões de agências de financiamento como o FMI e o BIRD, vêm repensando seus modelos de provisão (tradicionais) de serviços públicos e em que bases? Estaremos diante de um momento de ruptura radical com os conceitos que sustentaram historicamente a existência dos serviços públicos, ou assistimos apenas a uma tentativa de o Estado diferenciar o que é intrínseco ao serviço público, do que pode ser transferido total ou parcialmente para o setor privado?

No momento em que se questiona a noção de serviços públicos e as próprias funções 
do Estado, assistimos à transformação de conceitos até então cristalizados e à emergência de novas concepções, cuja dimensão e alcance ainda não somos capazes de avaliar. É possível privatizar sem perder o domínio sobre o espaço público e o controle do papel social dos serviços?

A resposta a essas inquietações varia, evidentemente, de um contexto a outro e de um serviço a outro. No entanto, algumas situações podem ser analisadas de modo crítico, procurando demonstrar as alternativas de equilíbrio e de manutenção de certos parâmetros nas formas de colaboração público/privado, centradas na criação de mecanismos particulares de regulação social.

Num esforço de repensar as fronteiras e as formas de relação entre os setores público e privado, este texto busca renovar a reflexão acerca das estratégias e dos objetivos dos atores envolvidos nessas relações, dos rumos que pode tomar esta fase atual de revisão por que passam os serviços públicos e de suas conseqüências possíveis. Pretende, também, abrir novas perspectivas para a compreensão das configurações dos modelos de gestão dos serviços públicos que se delineiam, não sem antes identificar certos elementos indispensáveis para o entendimento dos diversos significados da relação público/privado, e enfatizar alguns conteúdos fundamentais das noções de espaço público, interesse público e serviço público (local), suportes essenciais das formas de intervenção do Estado na vida social.

\section{IMPLICAÇõES DE UM CONCEITO}

Temos assistido, nas duas últimas décadas, a uma onda de privatizações (no sentido amplo do termo) de empresas e serviços públicos, utilizando-se vários modelos bastante diferenciados. Dentro da variedade de situações encontradas, o tema da privatização, de modo geral, tem-se situado na confluência de várias disciplinas que, por falta de terminologia mais precisa, utilizam o mesmo termo para designar diferentes formas de cooperação entre o setor público e atores privados.

- termo privatização de serviços, utilizado indistintamente, comporta imprecisões e ambigüidades, sobretudo quando é confundido com delegação, parceria, terceirização. Em muitos casos, o debate ideológico e passional que opõe ainda defensores da presença do Estado em certos setores e partidários da iniciativa privada, poderia ser relativizado com a compreensão de duas questões que nos parecem esclarecedoras dos vários sentidos das situações que envolvem setor público, setor privado e serviços públicos: 
1) quem é responsável pela criação e organização dos serviços, e

2) de que maneira se realiza sua operação ou prestação.

Esta distinção, relativamente simples, que separa dois níveis de ação, o da iniciativa de criação do serviço e o da sua produção, facilita a compreensão das formas de participação pública e privada nos serviços públicos. A iniciativa e a produção são atividades diferenciadas. A iniciativa, que os americanos designam por provision (provide), significa oferecer e estipular as condições de prestação do serviço; produção é a utilização dos fatores e dos recursos necessários à realização efetiva do serviço e à sua distribuição (Terny et Prud'homme, 1990).

A iniciativa e a produção foram, em muitos setores no passado, inteiramente privadas, em casos típicos de privatização stricto sensu. Na maioria das situações atuais é o organismo público que tem a iniciativa de criação do serviço, dispõe da autoridade para designar quem o produzirá e com quais modalidades de prestação. Tradicionalmente o poder público vem assumido todas essas etapas, configurando o caso clássico de gestão direta ou gestão pública.

Quando o serviço é criado pelo setor público e produzido por empresa privada, estamos diante de uma forma de gestão delegada, na qual a iniciativa e o controle permanecem públicos. O poder público delega apenas a função de produção, mas não delega a autoridade sobre as condições de produção e de prestação, não renunciando, de modo algum, à sua responsabilidade sobre o serviço. $\mathrm{O}$ serviço continua público e, se for necessário, em função do interesse coletivo, o poder público pode, a qualquer momento, revogar a delegação.

O Quadro 1 permite visualizar melhor essas considerações.

\begin{tabular}{|c|c|c|c|c|c|c|}
\hline Iniciativa & \multicolumn{4}{|c|}{ pública } & \multicolumn{2}{|c|}{ privada } \\
\hline produção & \multicolumn{2}{|c|}{ pública } & \multicolumn{2}{|c|}{ privada } & \multirow{2}{*}{\begin{tabular}{|l|}
\multicolumn{1}{|c}{ pública } \\
concorrência \\
entre \\
monopólios \\
públicos
\end{tabular}} & \multirow{2}{*}{\begin{tabular}{|l|}
\multicolumn{1}{|c|}{ privada } \\
concorrência \\
permanente \\
(mas pode ser \\
imperfeita)
\end{tabular}} \\
\hline mercado & \multicolumn{2}{|c|}{ monopólio público } & $\begin{array}{l}\text { monopólio } \\
\text { permamnente }\end{array}$ & $\begin{array}{l}\text { monopólio } \\
\text { temporário } \\
\text { ou } \\
\text { concorrência } \\
\text { periódica }\end{array}$ & & \\
\hline $\begin{array}{l}\text { modo de } \\
\text { gestão }\end{array}$ & $\begin{array}{l}\text { gestão } \\
\text { direta }\end{array}$ & $\begin{array}{l}\text { gestão } \\
\text { indireta }\end{array}$ & \multicolumn{2}{|c|}{ gestão delegada } & $\begin{array}{l}\text { não } \\
\text { significativo }\end{array}$ & $\begin{array}{l}\text { gestão } \\
\text { privada }\end{array}$ \\
\hline $\begin{array}{l}\text { forma } \\
\text { jurídica }\end{array}$ & $\begin{array}{l}\text { adminis- } \\
\text { tração } \\
\text { pública }\end{array}$ & $\begin{array}{l}\text { empresa } \\
\text { pública, } \\
\text { SEM } \\
\text { autarquia }\end{array}$ & \multicolumn{2}{|c|}{$\begin{array}{l}\text { concessão, permissão } \\
\text { licitação, contrato de } \\
\text { prestação de serviços }\end{array}$} & $\begin{array}{l}\text { vendas } \\
\text { residuais das } \\
\text { administrações }\end{array}$ & $\begin{array}{l}\text { privatização } \\
\text { do serviço }\end{array}$ \\
\hline $\begin{array}{l}\text { forma de } \\
\text { controle }\end{array}$ & pública & pública & \multicolumn{2}{|c|}{ pública } & $\begin{array}{l}\text { não } \\
\text { significativo }\end{array}$ & $\begin{array}{l}\text { leis de } \\
\text { mercado }\end{array}$ \\
\hline
\end{tabular}

Quadro 1: Modelos de gestâo de serviços públicos. (Fonte: Cavalcanti Fadul, 1994) 
Textos de direito administrativo brasileiro indicam a existência de três modalidades clássicas de delegação, que pode ser considerada uma forma atenuada ou discreta de privatização: a concessão, a permissão e a autorização. Resumidamente, a concessão é uma delegação legal ou por contrato bilateral estabelecido entre o poder público concedente e a empresa privada ${ }^{(1)}$ A permissão é forma de delegação definida por ato unilateral (o termo de permissão), discricionário e precário, podendo a qualquer momento ser modificado ou revogado sem possibilidade de contestação do permissionário. O serviços autorizados são também delegados por ato unilateral, precário e discricionário do poder público, para atender a interesses coletivos transitórios ou urgentes, podendo ser supresso a qualquer momento (Meirelles, 1991).

\section{Espaço Público x Domínio Público}

Todas as empresas privadas que gozam de determinados tipos de concessão, de permissão, ou mesmo que prestam serviços, são um grupo de atores que podem utilizar o domínio público, sob certas condições contratuais, a fim de oferecer, em acordo com os governos locais, certos serviços ou informações. É o caso dos transportes urbanos, da coleta do lixo, da iluminação pública, das redes de água e esgoto, de gás, de telefone, certos estacionamentos, de espaços publicitários, de placas de sinalização e de outros equipamentos urbanos.

As mudanças nos modelos de gestão dos serviços públicos locais podem pôr em risco as estruturas do espaço público, ou seja, o conteúdo do que vinha sendo considerado até então como público. O espaço público, como espaço aberto a todos, é espaço teórico que, praticamente, já não existe. Mesmo os espaços públicos mais abertos e mais complexos só são, potencialmente, acessíveis a todos. Com isso, parte cada vez maior de espaços públicos está sendo dissociada do domínio público. Estado (poder público) e cidadãos podem estar perdendo, respectivamente, seus meios de controle, de livre acesso e de utilização de grandes parcelas de espaço público, justamente aquelas que correspondem aos espaços urbanos mais dinâmicos.

Determinados instrumentos jurídicos são utilizados para diferenciar o que é regido pelo código civil de direito privado, do que faz parte do código administrativo de direito público. Mas, por trás desses critérios formais, existe uma imbricação de direitos de uso, uma multiplicidade de parceiros que se beneficiam de direitos particulares (contratos de prestação de serviço, concessões, permissões, e outros) e grande diversidade de formas de gestão, de tarifação, de delegação, fazendo com que, a priori, seja difícil distinguir o espaço público do espaço privado. ${ }^{(2)}$ 
Essa situação de imbricação de direitos torna mais complexa a participação cada vez mais crescente de atores privados, nas múltiplas formas de parceria com as municipalidades para a produção dos serviços públicos, fazendo do espaço público o lugar das grandes contradições entre interesses privados e o interesse público que decide, pela via legislativa e da regulamentação, os limites do direito privado. O espaço público torna-se, então, o lugar de conflitos potenciais e objeto de negociação permanente entre os usos de fato, considerados pelos cidadãos como direitos adquiridos ou naturais, como: livre-circulação, proteção, segurança, justiça, harmonia, salubridade, serviços, comodidades...

Traduzido muitas vezes como espaço visível, acessível, como lugares públicos, denominados em seguida de espaços públicos urbanos ${ }^{(3)}$ - ou, também, como espaço imaterial, expressão flutuante da organização social, da organização de relações particulares entre presenças, atividades e trocas (Plan Urbain, 1988), o espaço público aparece, afinal, como modalidade de representação pública do poder, essencialmente centrada na imagem do Estado. Nesses termos, a criação da noção de espaço público tem raízes muito mais profundas na própria fundamentação da noção jurídica de serviço público e da noção de poder público, amplamente empregada para se referir ao conjunto das organizações públicas, expressando a superioridade da administração sobre seus administrados (Chevallier, 1987).

Com efeito, o conceito de domínio público, nascido na França com o advento do Estado moderno, procurava separar do domínio total do Estado o que era propriedade privada do príncipe, ou seja, o domínio privado do Estado. O domínio público era o domínio que servia aos usos públicos e que deveria ser preservado para essas finalidades. Hoje, nos países democráticos, "o domínio total do Estado tornou-se <<Allmend〉>, domínio comum (...), e em seguida, domínio público" (Fischer E., 1924). O domínio público são as coisas públicas, das quais o Estado dispõe com base no direito público, e que constituem o que chamamos hoje de interesse público, o qual o Estado é obrigado a defender e sobre o qual se fundamenta o conceito jurídico de serviço público.

Nesse sentido, a criação dos serviços públicos é classicamente associada à existência de certas necessidades sociais objetivas e justificada pela suposição ideológica de uma missão de interesse público. Conseqüentemente, o Estado benfeitor, movido pelo interesse público, intervém na vida social para desempenhar certas funções num determinado espaço, criando os serviços públicos e colocando-os ao alcance de todos.

O serviço público surge, também, como um dos mecanismos do poder público para assegurar sua autoridade sobre o domínio público. Enquanto instrumento da intervenção do Estado, o serviço vai-se constituir na organização que utiliza para 
impor a ordem pública e social; o domínio público passa a ser o instrumento material do qual se dota para a realização de suas funções.

Em determinadas circunstâncias, apesar de movida pelo interesse público, a intervenção do Estado na criação de determinado tipo de serviço aparece, claramente, como necessidade de reafirmar sua soberania sobre o espaço público, o espaço que expressa sua imagem e, enfim, o representa. Sem pretender discutir exaustivamente as teorias dos serviços públicos, mas apenas procurando ilustrar esta perspectiva, fazemos referência à criação dos serviços públicos de limpeza urbana.

No final do século passado, início deste, se olharmos rapidamente a história de cidades ocidentais como Rio de Janeiro, Salvador, Paris ou Londres, verificamos que a forma primitiva de eliminação dos resíduos domésticos era, simplesmente, transferilos do espaço interno privado, para um espaço exterior, originalmente um no man's land. Eliminar, significava apenas, distanciar-se, segundo o princípio do out of sight out of mind, utilizando para isto um espaço qualquer, livre, de ninguém ou de todos. Isto significava depositar os resíduos de forma aleatória nos rios, nas praias, em terrenos desocupados ou mesmo nas ruas.

O lixo invade progressivamente os limites dessas cidades; o poder público tenta disciplinar as práticas individuais, proibindo o uso indiscriminado desses espaços, com preocupação muito mais estética ${ }^{(4)}$ do que propriamente de satisfazer a necessidade imperativa e real da população, de não coabitar com a sujeira e distanciarse dos seus resíduos com certa comodidade. Sob a bandeira de salvaguardar o interesse público, numa ação normativa e de controle, o Estado vai impondo códigos e convenções de funcionamento, mudando concepções e práticas, incorporando novos valores, numa forma de apropriação desse espaço considerado até então sem dono, à medida que cria normas e regras para os habitantes se desembaraçarem de seus resíduos particulares. Numa conquista progressiva, amplia suas prerrogativas para assumir diretamente a produção do serviço, atribuindo-lhe características de serviço público, numa demonstração de autoridade apoiada no direito, sob a égide do interesse público.

\section{Modelo de TransiçÃo}

Esse modelo, de serviços públicos criados e produzidos diretamente pelo próprio Estado, funcionou de modo satisfatório até o final da década de 70, quando uma série de acontecimentos de cunho econômico e cultural vieram desestabilizá-lo. O resultado é a perda da capacidade de atendimento das necessidades básicas e das pressões de todos os setores sociais.

Crise ou momento de transição, inflexão ou necessidade de modificação de estruturas sócio-econômicas e políticas, o Estado do bem-estar atinge seus limites e esgota suas 
potencialidades. Suas bases de financiamento das despesas sociais vão sendo consumidas pela crise econômica e, do mesmo modo, a capacidade de gerenciamento parece declinar, seja em função do peso excessivo das estruturas burocráticas e da inadequação dos métodos de gestão, seja como consequiência do envelhecimento dos mecanismos políticos tradicionais e da política social.

Várias alternativas são buscadas no sentido de desburocratizar, de racionalizar e reorganizar a gestão de certos serviços através da reestruturação das arquiteturas institucionais e jurídicas das organizações públicas, da descentralização, da desregulamentação, desregulação e autonomização, mas a incorporação de empresas privadas e o reforço aos mecanismos de mercado parece ganhar intensidade em contextos os mais diversificados.

As razões que levam os poderes públicos a recorrer à iniciativa privada podem ser resumidas globalmente em alguns fatores econômicos e culturais. De um lado, as despesas públicas aumentaram consideravelmente e passaram a ser contestadas pelos contribuintes; a interferência de objetivos sociais com os objetivos econômicos vai, por sua vez, resultar em baixa produtividade do setor público; as empresas passam a exercer pressão sobre os mercados públicos em função de suas estratégias de crescimento. Do outro lado, as inovações tecnológicas, sobretudo no campo dos transportes e das telecomunicações, favorecem a emergência de uma cultura da autonomia: assistimos à mudança de valores coletivos, os mercados se transformam, fazendo surgir formas flexíveis de gestão (Lorrain, 1995).

Junte-se a isso a necessidade que experimenta todo sistema social de se renovar para evitar sua própria esclerose, para termos o quadro de crise no sistema e, paralelamente, o desejo quase instintivo de autopreservação, fazendo retornar aos modelos econômicos clássicos, que embora não tenham sido capazes de atender às demandas sociais crescentes, nem prover a proteção social desejada, poderiam, pelo menos teoricamente, conduzir a um desenvolvimento equilibrado.

Com o crescimento dessas novas formas de gestão, que incluem o setor privado na sua operação, os serviços nos centros urbanos passam atualmente por modificações profundas. Em muitos casos, a gestão desses serviços é dominada pela incorporação de princípios de mercado à esfera pública e marcada pela adoção de instrumental da administração de empresas, com programas de qualidade que procuram elevar os níveis de produtividade das organizações públicas.

O mercado dos serviços urbanos vem, também, sofrendo grandes transformações, não só em nível local mas em nível internacional. Setores antes especializados procuram transformar-se, diversificando seu ramo de atividade. As grandes empresas, ao exportar 
seus métodos de trabalho, seus princípios e suas normas, vão redefinindo as regras do jogo no campo da gestão desses serviços.

Até que ponto, transferindo a produção desses serviços para o setor privado, o Estado não estará perdendo o direito e o domínio sobre o espaço público que construiu? Como assegurar os direitos mais básicos dos cidadãos, em um regime de eficiência produtiva da iniciativa privada? Como garantir a equiidade territorial? ${ }^{(5)}$

Um dos grandes argumentos dos partidários da gestão pública dos serviços coletivos, assumidos e assegurados pelo Estado, é justamente o seu caráter não mercantil, que permite atender às aspirações do público com vantagens sociais, igualdade de consumo e eqüidade, em contraste com o serviço privado, cuja lógica de mercado e padrões de qualidade e produtividade é marcadamente indutora de desigualdades no acesso e no consumo. A participação do setor privado na produção desses serviços poderia criar tensão permanente, ou seja, a de conciliar o papel do Estado, que visa a garantir a legitimidade e a coesão social, com a ação do setor privado, cujos objetivos previamente determinados, se norteiam pela busca do lucro e da sua continuidade econômica. Saímos de uma lógica de equilíbrio orçamentário das finanças públicas, para uma lógica do lucro máximo em situação ou ambiente concorrencial.

Como o poder público pode organizar a provisão de seus serviços, de modo que assegure:

1) igualdade no acesso aos serviços, indiscriminadamente, a todos os usuários e em todo o território no qual ele é oferecido?

2) que os serviços públicos concorram para o desenvolvimento equilibrado, compensando as desigualdades sociais?

\section{Perspectivas de Eqüidade num Contexto de Privatização}

A participação do setor privado pode modificar o contex to no qual o poder público organizava o equilíbrio ou os desequilíbrios sociais e espaciais, dentro de determinado tipo de compromisso social, em que não era preciso averiguar a fundo os que pagavam pelos outros, mas que considerava, em nome da igualdade, que todos deveriam receber o mesmo tipo de serviço, em todos os lugares, produzido com a mesma tecnologia.

No entanto, os serviços se diversificam com as inovações tecnológicas e com a segmentação da demanda e dos mercados. Diversifica-se também a oferta, fazendo surgir serviços diferentes oferecidos por um ou mais operadores. ${ }^{(6)}$ A imagem de 
serviço público, enquanto serviço básico ao qual todos têm direito, oferecido indistintamente a todos os consumidores e universalmente acessível, começa a parecer utópica.

Por outro lado, a própria fronteira dos serviços públicos parece estar se deslocando. É possível que haja serviços públicos que perderam esta característica e outros que estão ingressando agora, nesta categoria. Será realmente possível encontrar um serviço, cujo preço seja o mesmo para todos os usuários e cuja capacidade de acesso e de consumo seja igual para uma família de renda modesta e para uma família de renda elevada?

As experiências de privatização na Grã-Bretanha, onde surgiram as primeiras iniciativas de maior porte, constituem um caso interessante no que diz respeito a esses fenômenos de disparidade espacial e social. As consequiências sociais e geográficas do processo de privatização dos serviços públicos na Grã-Bretanha nos dão a primeira visão dos riscos de mudança radical no sistema e do papel fundamental do Estado enquanto agente regulador, de modo que se assegure um serviço igual para todos.

Até os anos 80, os serviços públicos na Grã-Bretanha eram produzidos e gerenciados pelo Estado, sob a forma de monopólios naturais, de forma que se garantisse a generalização dos serviços e condições para melhor desenvolvimento industrial. Durante o governo Thatcher, esse panorama muda radicalmente. ${ }^{(7)} \mathrm{O}$ conjunto dos serviços (água, gás, energia e telecomunicações) é sacudido por processo de privatização que os transforma em um dos setores mais rentáveis da economia, suscitando o interesse de atores privados os mais diversos, criando um conjunto complexo de empresas privadas e agências reguladoras, numa situação da qual derivam três tipos de dicotomia (Graham \& Marvin, 1994).

1) Certos setores (como água e energia) têm formas de organização baseadas no governo local, enquanto outros são organizados a partir de uma lógica que privilegia a escala nacional ou mesmo internacional (gás e telecomunicações).

2) O princípio tradicional da subvenção cruzada, que assegurava acesso das classes sociais menos favorecidas e daqueles que viviam em localidades distantes, encontra-se invertido em razão da concorrência entre as empresas, que tendem a conquistar os grandes consumidores com tarifas preferenciais.

3) Dois cenários antagônicos apresentam-se como consequiências possíveis: ou se caminha para a integração intersetorial e a aliança entre empresas, ou 
para a fragmentação das atividades e a concentração da concorrência em determinados pontos do território.

Essas mudanças podem afetar a própria concepção dos serviços antes baseada na idéia de serviço igual para todos. Atualmente os serviços públicos repousam numa lógica de rentabilidade e privilegiam a capacidade de pagamento dos usuários da qual derivam, segundo Graham \& Marvin (1994), dois fenômenos irremediavelmente ligados: o cherry picking e o social dumping.

Cherry picking, segundo os autores, é o processo de luta das empresas para a dominação das zonas mais rentáveis ou em acelerado crescimento. Isso conduz ao surgimento de estratégias de novas alianças com empresas estrangeiras ou multinacionais, o que não é especificidade da Grã-Bretanha, mas inscreve-se, pelo contrário, no fenômeno de globalização da economia. Do ponto de vista espacial, as zonas cherry picked se beneficiam de tarifa preferencial e de prioridades em matéria de inovações tecnológicas, com relação aos serviços em outras zonas pouco atraentes para os investidores. A eliminação das subvenções cruzadas reforça esta dicotomia territorial.

Por social dumping o autor procura designar o desprezo pelas classes sociais mais pobres, que não são nem grandes consumidores de serviços, nem utilizadores de tecnologias sofisticadas, mas que são obrigadas a pagar tarifas elevadas pelos serviços de base e, se não têm condições de pagar, terminam por serem excluídas do acesso a esses serviços. A era do serviço igual para todos terminou. A água, o gás, a energia elétrica e as telecomunicações aparecem agora como bens de consumo duráveis.

A principal conseqüência do modelo cherry picking \& social dumping reside na criação de guetos, onde o acesso aos serviços, incluindo-se os menos sofisticados, torna-se cada vez mais problemático. O princípio das subvenções cruzadas perdeu o sentido com a privatização e, conseqüentemente, a questão dos auxílios dados aos consumidores menos solváveis não é mais tratada no âmbito da gestão dos serviços, mas no âmbito das políticas sociais do Estado.

Neste ponto, a noção da eqüidade ganha importância, pois tem relação direta com a privatização de serviços não só no sentido amplo, mas com as diversas formas de delegação e com os níveis de regulação. Os governos locais são obrigados a se dotarem de novas competências, de novo instrumental para regular e reduzir os desequilíbrios.

Novas formas de regulação vão emergindo numa espécie de jogo entre estabilidade de regras e capacidade de auto-regulação, reconfigurando os sistemas de atores e em 
particular as empresas. A ação pública, em função de seus próprios objetivos, redefine as características dos serviços.

É preciso saber se os atores envolvidos estão conscientes das mudanças nas relações sociais e nas relações de força. Essas modificações vão além de simples repartição de papéis na distinção entre público e privado, mas vão implicar, necessariamente, na redefinição de competências e de responsabilidades entre esses atores.

Não se pode, com efeito, admitir simplesmente a participação de um setor privado eficaz, mas que, na sua ação, provoque desigualdades e exclusões, nem um setor público social que intervenha, em seguida, apenas para reparar os danos causados pela falta de uma ação preventiva. Esta ação preventiva poderia nascer da construção de mecanismos eficazes de regulação de serviços públicos operados por empresas privadas (Lorrain, 1995).

\section{O Alcance da Regulação}

A nova influência do setor privado na gestão dos serviços públicos urbanos cria novo patamar de ação coletiva e introduz o debate sobre a regulação. $\mathrm{O}$ modelo tradicional está sendo substituído por outro tipo de regulação, baseada em relação ainda informal, cujos agentes principais são o poder público e as empresas, mas que depende de forte atuação da sociedade.

A organização dos mercados de serviços públicos supõe, desse modo, a existência de três elementos que se combinam, variando o peso de cada um deles de acordo com o contexto: a figura formal do regulador (que é atribuída em primeiro plano ao setor público); os mecanismos de regulação (instrumentos jurídicos capazes de controlar possíveis abusos das empresas privadas); e a auto-regulação (princípios internos que auto-limitam a força das empresas e do setor público na manutenção da estabilidade do mercado).

O regulador é aquele que estabelece a estrutura da cadeia de produção e que cria seu próprio espaço dentro dessa cadeia. É quem, em princípio, define a forma de relação entre os elos da cadeia, sendo ao mesmo tempo um deles. Nesses termos, o regulador teria de ter certa independência tanto do poder político quanto da empresa que regula. A duplicidade de papéis da figura do regulador e a interferência do poder político e econômico nas suas ações criam dificuldades de coordenação e de manutenção da relação de equilíbrio com a empresa privada prestadora de serviços, que goza da vantagem essencial de conhecer concretamente as modalidades de produção do serviço. ${ }^{(8)}$ 
Para os anglo-saxões, por exemplo, a figura do regulador é preponderante e essencial; há pequeno espaço para os mecanismos de regulação e os princípios da auto-regulação não são explicitados. Esse tipo de regulação procura estruturar o mercado e estimular a concorrência, mas não se apresenta como mecanismo capaz de promover o equilíbrio, mas sobretudo como arma estratégica para transformar a estrutura de mercado (Lorrain, 1995).

$\mathrm{Na}$ França, no entanto, a figura do regulador oficial (instituições específicas de regulação) praticamente inexiste. No entanto, o sistema se regula porque existem mecanismos de regulação que são reforçados pela auto-regulação. O que norteia a França não é a lógica de regulação, mas a lógica de contrato, que serve também à delegação, na qual o poder público firma contrato com empresa privada, ou com parceiro; esse contrato comporta engajamentos recíprocos: o Estado francês é ainda empreendedor, planejador e prestador de serviços, muito mais preocupado em gerenciar do que em regular, mesmo quando delega a prestação de serviços ao setor privado. Segundo Lorrain (1995), o que distingue a organização dos serviços nesses dois países é sobretudo esta: a França desenvolveu uma cultura que privilegia o Estado e os ingleses, uma cultura que privilegia o mercado. Essas características vão implicar estruturas e instâncias bastante diferenciadas de regulação.

Para uns, a regulação pode ser apenas regulamentação, fundamentada em dispositivos jurídicos precisos estabelecidos de forma vertical, normativa e unilateral. Esses mecanismos de regulação formais (normas, contratos e acordos) podem ajudar a reduzir as incertezas, permitindo que as empresas prevejam seus investimentos em função da duração de um contrato. No entanto, a evolução atual deu ao termo regulação um sentido novo, de recomposição das relações entre Estado, mercado e empresa privada.

A regulação deve ser analisada como forma de coordenação baseada em mecanismos coletivos, que procuram criar relações estáveis entre os atores que não sejam baseadas apenas no dinheiro, nem na competição, ou no antagonismo. São relações ainda informais de parceria que culminam em acordo tácito que permite conduzir, de forma harmoniosa, a ação coletiva. A direção que estes modos de regulação emergentes possa dar ao processo de condução das políticas sociais não está ainda determinada social ou politicamente, mas os novos mecanismos de regulação devem sobrepor os objetivos sociais às atividades econômicas, devendo dispor de instrumentos que facilitem a manutenção dos valores de eqüidade, fazendo surgir novo tipo de compromisso social. Nesse contexto, a reforma do Estado e a conseqüente redefinição dos serviços públicos surge quase como imperativo. As estruturas atuais devem ser questionadas, em debate em que o setor público é, ao mesmo tempo, agente de mudança e elemento a ser reformulado. 


\section{CONCLUSÃo}

A tendência atual à delegação e à concessão de certos serviços e de fragmentos de espaços públicos se confirma. ${ }^{(9)} \mathrm{A}$ idéia de que a cidade pode se autofinanciar é partilhada por muitos políticos e muitos administradores públicos. O princípio da criação de espaços gratuitos de uso comum, com dotações e recursos orçamentários globais, parece estar sendo substituído, cada vez mais, por fórmulas de tarifação de espaço-e-tempo de uso (tarifas de transporte, do uso de grandes infra-estruturas rodoviárias, de sanitários públicos, estacionamentos, pedágios, espaços publicitários). O espaço público gratuitamente aberto a todos se está transformando em novo tipo de serviço público, com tarifa diferenciada de acordo com os usos, horários e localização.

Por outro lado, assistimos também à transformação profunda nos mercados de serviços urbanos, que passa pelo fenômeno da globalização, em recomposição progressiva desses mercados em torno de grandes grupos internacionais. Esses mercados que foram, durante muitos anos, organizados em função de uma cultura pública nacional, vêm sendo progressivamente dominados por operadores que ultrapassam as fronteiras dos países. Essas transformações conduzem também à reorganização das cidades em vários sentidos.

Cidades estruturadas em grandes redes estão emergindo, em sistema de atores articulados e hierarquizados. O espaço público tornou-se sinônimo de imagem da cidade, na confluência de diferentes interesses políticos, econômicos, urbanísticos e culturais mais ou menos contraditórios, significando para os mesmos atores tanto um espaço de cidadania, suporte de múltiplas práticas, mediador de diferentes tensões, quanto um espaço de redes consideradas como serviço coletivo que gerencia nas melhores condições e pelo menor custo.

Em virtude dessa complexidade crescente de sistemas de propriedade, de gestão e usos e da multiplicidade de parceiros envolvidos, os diferentes atores, cada vez mais, buscam formas de ação contratual e de conciliação, em iniciativas que dão lugar à criação de fórmulas de cooperação específicas. Esse fenômeno, que não é restrito a um país ou a um tipo de serviço, tem provocado modificações profundas nos modos de gestão dos serviços, produzidos e distribuídos em meio urbano.

Cada vez mais o poder público vai desenvolvendo tipos de negociação variados com o setor privado. Essas experiências provam que os governos locais estão conscientes da necessidade de implicar os parceiros privados nas diferentes etapas 
da organização e da transformação dos serviços públicos.

Apesar dessas particularizações da relação público/privado serem ainda muito recentes para que possamos antever todos os seus desdobramentos, um esforço continuado de observação e análise deve ser feito nesse sentido. As disposições contratuais precisam ser mais bem especificadas, porquanto, como as estratégias de cada um dos atores são diferentes, certos tipos de acordo ou de contratos correm o risco de satisfazerem interesses econômicos ou políticos mais do que os interesses de organização da cidade. O desafio é, portanto, saber encontrar, nas alternativas existentes (descentralização, transferência de responsabilidades para o setor privado, utilização de mecanismos de mercado, contratos, e outros), as fórmulas mais flexíveis e socialmente mais eficazes.

\section{NOTAS}

${ }^{1}$ Modernamente o poder público outorga concessões de serviços, por lei ou decreto, a entidades autárquicas e para-estatais, o que constitui inovação do sistema tradicional das concessões por contrato (Meirelles, 1991, p. 334).

${ }^{2}$ Originalmente, com o surgimento da cidade grega, a oposição entre o que era público e o que era privado era marcante, centrando-se na distinção clara entre o que pertencia a cada cidadão (idion) e o que era comum (koinon). A cidade (koinonia politike) encarnava esta esfera pública helênica, como esfera da palavra e da ação-em-comum, opondo-se à esfera privada de oikos, da família e do conjunto familiar (Chanial, 1992). Historicamente, também, as transformações que esse espaço público experimenta com a evolução dos modos de vida e de seus usos sofre, na sua demarcação, confrontação permanente entre público e privado.

${ }^{3}$ Espaços abertos, exteriores à habitação, complementares às edificações públicas e privadas (ruas, praças, jardins públicos, avenidas, passagens, o entorno de conjuntos habitacionais) que se opõem aos prédios públicos (prefeitura, escolas, museus, teatros, serviços públicos) e aos lugares públicos de cunho privado (cafés, cinemas, estações, shopping centers...).

${ }^{4}$ Historiadores criticavam sistematicamente o odor insuportável e a sujeira que dominavam essas cidades, o que denegria a imagem do poder público que, pela via normativa, editava atos oficiais para tentar disciplinar a população com relação ao uso do espaço público (Cavalcanti Fadul, 1994).

${ }^{5}$ Significaria dizer o mesmo serviço em todo o território, com acesso igual para todos, com a mesma tecnologia e com o mesmo preço.

${ }^{6}$ Um aspecto interessante dessa situação é que, a partir do momento em que há diversificação de serviços e diversificação de prestadores de serviço, as municipalidades tornam-se também clientes das empresas privadas que, muitas vezes, passam a oferecer-lhes serviços que antes não existiam.

${ }^{7}$ Nos meados dos anos 80, a administração Thatcher vendeu a British Gas, British Telecom, Jaguar, British Airways, o Sealink Ferry Service, todas ou parte de suas ações na British Sugar, British Aerospace, British Petroleum e British Steel, bem como um milhão de imóveis públicos e várias 
empresas de utilidade pública (Donahue, 1992, p. 14).

${ }^{8} \mathrm{O}$ caso dos serviços de limpeza urbana da cidade de Salvador é bastante ilustrativo das dificuldades de regular a ação de empresas privadas que prestaram serviços à municipalidade, dentro de uma cultura extremamente marcada por compromissos com grupos de interesse, alianças políticas e acordos econômicos (Cavalcanti Fadul, 1994).

${ }^{9}$ Espaços estão sendo vendidos ou concedidos a empresas privadas. Muitos desses espaços serão fechados e seu acesso concedido mediante pagamento (privatização de rodovias federais, por exemplo).

\section{ReFERÉnCIAs Bibliográficas}

CAVALCANTI FADUL, E. M. Nouvelles géometries dans les modes de gestion des déchets solides au Brésil: une étude de l'évolution des relations entre la puissance publique et ses partenaires privés.Paris, 1994.Tese de Doutorado Nouveau Régime, Universidade Paris XII - Institut d'Urbanisme de Paris.

Participação do setor privado na produção de serviços públicos: a dinâmica das formas de regulação. In: XXX Assembléia do CLADEA, 1995, São Paulo. Anais ... São Paulo: CLADEA 1995.

\section{CHANIAL, P.}

Espaces publics, sciences sociales et démocratie. Quaderni, n.18, 1992.

CHEVALLIER, J.

Le service public. coll Que sais-je? Paris: PUF, 1989.

\section{DIDIER, $\mathrm{M}$.}

Evaluation des performances des diverses modes de gestion des services publics locaux - Etudes de cas. In: Premier Colloque International des Services Publics, 1990, Paris. Actes... Paris, 1990.

DONAHUE, J. D.

Privatização - fins públicos, meios privados. Rio de Janeiro: Zahar, 1992.

FISCHER, E.

Les concepts de "domaine public" et de "régie publique". Les Annales de la Régie Directe, v.16, n.175-177, p.1-11, Nov. 1923/ Jan. 1924.
GRAHAM, S.

MARVIN, S.

Cherrry picking and social dumping: utilities in the 1990's. Utilities Policy, Apr.1994.

\section{LORRAIN, D.}

L'extension du marché. In: LORRAIN D., STOKER, G. La privatisation des services urbains en Europe. Paris: La Découverte, 1995.

MARTINAND, C.

L'expérience française du financement privé des equipements publics. Paris: Economica, 1993.

MEIRELLES, H. L.

Direito administrativo brasileiro. São Paulo: Editora Revista dos Tribunais, 1991.

PLAN URBAIN.

Espaces publics. Paris: La Doc. Française, 1988.

TERNY G.

PRUD'HOMME, R.

Performances et modes de gestion des services publics locaux. méthodes et témoignages. In: Premier Colloque International des Services Publics, 1990, Paris. Actes ... Paris, 1990. 